\title{
Effective Ways to Promote College Work of Managing and Educating People under New Circumstances
}

\author{
Yijie Qi \\ College of Horticulture, Jilin Agricultural University, Changchun, 130118 \\ qyj101@126.com
}

Keywords: New Circumstances; Colleges; Managing and Educating People; Paths

\begin{abstract}
The government report of 18th party congress pointed out that the fundamental task of higher education is to establish morality and cultivate people. In the new era when information technology develops very quickly, it is also the basic direction of managing and educating people. Managing and educating people takes a long time and is tough, which needs the mutual cooperation between schools, families and society and they have to cooperate in different sectors. The author studies on its main connotation of and concrete measures and establishes a diverse platform to manage and educate people, aiming to contribute to its work.
\end{abstract}

\section{Introduction}

For colleges, cultivating outstanding talents is the main task to satisfy the information need of the time, which yet takes a long time and is very tough, asking cooperation from many parties. Just as what Yi Hong, deputy of the national people's congress and president of Southeast University is calling, the two directions ask to present the requirement of times while cultivating talents and refer to the social development; concerning different personalities of students, we have to carry out individual training to satisfy diverse requirements of the society. However, this strong calling is actually demonstrating deep worry of the talents quality. In reality, the traditional pattern to manage and educate people still prevail and imperfect system and poor cultivation awareness still exist, which actually constraint talents cultivation. Based on the above problems, we can say that it is not beneficial to develop the economy. Under such circumstance and new condition, various parties should take the initiative to promote the work of managing and educating people.

\section{Why Do Tragedies Happen so Frequently}

In 2015, two undergraduates successfully got admitted to key colleges to further their study after paying tireless efforts and their teachers, classmates, family members felt happy for them. However, they got caught after four days when they entering the college because of being an accomplice in stealing and they got dismissed from school. Just as an old saying goes, a single slip can cause a lasting sorrow, their mistake destroyed their promising future and brought shame on their colleges as well as their families. After the college knows the fact, mangers of the college did not try to cover the fact and organize a topic about how to shape the image of students so as to let other students draw a lesson. At present, there are common occurrences. For example, on April 2013, there was a poisoning case in Fudan University. A graduate called Lin Senhao poisoned his roommate and made him die. Afterwards, he was sentenced to death and his lifelong political power was taken away. More typical things are Ma Jiqjue killing case happened in 2004 and cases when students could not get love from the one they want and disfeatured them.

Even though these cases happened in some students, which can reflect social problems, and the college work of managing and educating students should not only focus on management but find out the root. To begin with, the guidance thoughts of colleges are biased. At present, there are not enough students resources while schools have to spend a lot to maintain the development and the competition among colleges is becoming more and more fierce. So, colleges are expanding the scale and have paid a lot of efforts to promote, sometimes ignoring students management, or even weigh materials more than students, showing in the following aspects: first, they did not put a lot of 
attention and ignore management without scientific management and they cannot deal with work with passion and prediction; second, colleges do not put enough funds and ignore to construct campus culture when they are engaged in winning students resources. In addition, they do not focus on managing and educating them. Most of the schools cannot correctly give students a clear position, thinking that it's the task of some individual departments to manage and educate them without considering from a overall perspective. Secondly, the college work of managing and educating students is not scientific and some staffs are not responsible, ignoring the spiritual civilization. Colleges still adopt traditional management and go extreme. For example, concerning the campus fighting, they will disguise a major accident as a minor one. As a result, students cannot realize the seriousness of school regulations. Furthermore, while teachers are punishing students, they just simply punish without ideological education. In colleges, students think the management is against them, which is killing their personality and is not beneficial to develop themselves.

\section{Effective Ways to Promote the College Work of Managing and Educating People}

\section{Strengthen Campus Culture Construction and Adhere to the Fundamental of Cultivating}

People. To strengthen the campus culture is to create individual campus culture under the guidance of education philosophy which can be implemented from the perspective of spiritual culture, institutional culture and material culture. The management culture construction is conducted based on mangers and relevant personnel's quality will inevitably cause big effect on students and management system will affect students' activities, which is the carrier of culture management. The management culture is the core of campus culture construction, which gradually affect students.

To begin with, colleges should gradually build management culture with educating people as the core, and perfect relative mechanism. In addition, the mechanism should integrate resources, including teacher resources, network resources and students departments. In addition, the regulation construction should be improved, which is the basic way to regulate students' behavior. While punishing and awarding students, carrying out student management and behavior management, it always plays a pivotal role.

Secondly, culture construction of campus should adhere to people-orientation. Educating people takes a long time, which needs a lot of participants, including school regulations, campus culture, and management work as well as parents supervision so as to cultivate all-round innovative talents. To adhere to people-orientation asks to pay attention to humanistic concern. College education is no longer only about grade, students want to demonstrate their personality and their thoughts become diverse, which ask teachers and colleges to pay more attention to them in terms of their ideas and emotion with guidance. Colleges can offer elective culture class to prefect students' personality. In the process of teaching, teachers and students are equal and teachers should pay attention to cultivate students' ability and teach students in accordance with their aptitude. Moreover, while constructing campus culture, we have to pay attention to the culture connotation and construct a good environment to educate people and combine culture $\&$ spiritual construction to natural environment construction. We can design cultural elements in the corridor to demonstrate the campus culture to let students feel that they are in a good environment and appreciate the honors of campus.

Improve the Quality of College Managers and Build a High-Quality Management Team. Regulations are carriers for colleges to manage and educate people and managers are leaders to implement management. In the process of management, they gradually affect students, so they have to be equipped with professional ethics such as cherish posts and devote wholeheartedly to work, seek reality and contribute them so as to improve their management quality.

To begin with, college management workers have to continually improve their professional ethics and morality construction is the guide to lead college staffs. The main responsibility of colleges is to cultivate young people with ideas and morality. Therefore, college mangers should improve their morality, and they have to set themselves as examples in terms of behavior, habits and concepts. Only in this way, can they be models to educate students and improve management level. 
Secondly, colleges should regularly carry out professional training for work staffs. At present, college education managers have different quality levels and some of them are not professional. They just do work based on their experience and are not familiar with students. Especially some old mangers, they have deep-rooted traditional concepts and can no longer satisfy the targets to cultivate talents. Besides, while enrolling mangers, colleges have to make strict levels and recruit professional and experienced ones and invest funds. Before recruiting them, they have to communicate with them often and improve their management level from different perspectives.

Establish a Platform to Manage and Educate People, Broaden Channels. Only by establish a diversified and multi-channel platform to manage and educate people, can we push the work. College work cannot be done immediately and directly, which needs cooperation of different parties. Therefore, by establishing a platform which can educate and manage people can effectively integrate the resources, which is of importance to perfect the mechanism. To begin with, by adopting this platform, we can effectively integrate network media resources and teachers and we can regularly update relative contents to guide people and it should be diverse and healthy for students to review easily. At the same time, we can set diverse service contents so that students can get the access to know what they cannot get usually and they can carry out communication. Network platform provides a more convenient access which can be the main place to manage and educate students. Secondly, the college work of managing and educating people can take advantage of the platforms such as wechat and weibo as well as BBS, which are attractive to students and colleges can release contents related to ideological and political education to affect students gradually. In addition, colleges are able to understand students' thoughts so as to provide related management work. By the way, colleges can enrich the contents by holding a forum, lectures etc to make students directly communicate with managers so that they will be able to carry out self-management. Or, they will participate in community and team event to make them close and guarantee the smooth work and meanwhile satisfy different needs of students.

\section{Conclusions}

The management work of college cannot accomplish at one stroke, which needs a long time efforts. As the old saying goes, Rome is not built in one day, and it takes ten years to grow trees, but a hundred to rear people. Under new circumstance, while facing various problems, colleges should try unremitting efforts to educate students and add funds in terms of resources, human resources and finance. What's more, college managers should build morality to set examples and adhere to the principle of human-orientation to continually strengthen campus culture and improve the comprehensive quality of managers. Furthermore, we can establish a network platform to manage and educate students for them to carry out communication and improve qualities.

\section{References}

[1] Zhang Yuewei. Explore on the college work of managing and educating people in new era [J]. Journal of Jiangsu Teachers University of Technology, 2011(7).

[2] Huang Shuai, Song Kaichun. Brief talk on the existing problems and countermeasures for the college work of managing and educating people $[\mathrm{J}]$. Jiannan culture: the latter half of the month, 2011(12).

[3] Zhao Jianhua. Few thoughts on strengthening college's work of managing and educating people [J]. Journal of ideological \& theoretical education, 2011(2).

[4] Wu Ying. Discuss on the college work of managing and educating people in the new era[J]. Magnificent Writing, 2013(24).

[5] Dong Peng, Liu Tao. Effective ways to improve college's work of managing and educating people in the new era [J]. Print Today Magazine, 2014(7):1-3.

[6] $\mathrm{Yu}$ Weimin. To create innovative education should adhere to human-orientation [J]Journal of 
Heilongjiang College of Education2003(4)

[7] Dong Zefang. Human orientation should be the first concept of running a school[J]China Higher Education

[8] Zhu Ping. Human orientation: higher education philosophy in 21st century [J]Journal of China Youth College for Political Sciences, 2000(4)

[9] Wang Jisheng. Discuss on the running concept of modern universities [J]Development Study, 2002(2)

[10]Liu Ping. Several thoughts to deepen the college internal system reform [J]Journal of Gannan Normal University, 2002(4)

[11]Zhao Chunlin. Ideological and political work should serve to cultivate students' comprehensive quality [J]Ideological and Political Education, 2003(1)

[12]Peng Zhenglu. Campus culture theory and construction in colleges [M]Chengdu: Press of University of Electronic Science and Technology, March 2002 